\section{Aid, exclusion, and the local dynamics of insurgency in Afghanistan}

\author{
Daniel Karell
}

\begin{abstract}
Division of Social Science, New York University Abu Dhabi \& Princeton Institute for International and Regional Studies, Princeton University
\end{abstract}

\section{Sebastian Schutte}

Zukunftskolleg and Department of Politics and Public Administration, University of Konstanz
Journal of Peace Research 2018, Vol. 55(6) 711-725

(C) The Author(s) 2018

Article reuse guidelines:

sagepub.com/journals-permissions DOI: $10.1177 / 0022343318777566$ journals.sagepub.com/home/jpr

@SAGE

\begin{abstract}
Can developmental aid bring peace to war-torn communities? The current literature is divided on this issue. One line of reasoning suggests that aid is likely to decrease violence by improving employment and prosperity, thereby making participation in conflict more costly. Another view cites evidence showing an association between aid projects and increased insurgent activity. Addressing this contradiction, we argue that different types of aid projects lead to different outcomes, as some projects foster an unequal distribution of benefits within communities. Our reasoning draws on qualitative accounts from conflict zones, recent research on how grievances associated with exclusion can foster civil war onset, and experimental findings regarding perceived inequity and punishment. Building on this scholarship, we use a recently developed event-matching methodology to offer insight from contemporary Afghanistan. Aid projects that tend to exclude portions of the community yield more insurgent activity in their wake than more inclusive projects. These results shed light on why some aid projects reduce violence while others do not, emphasizing that efforts to 'win hearts and minds' can be a source of both contentment and contestation.
\end{abstract}

Abstract

\title{
Keywords
}

Afghanistan, development aid, event analysis, grievances, insurgency, matching

\section{Introduction}

Can developmental aid bring peace to war-torn communities? Despite myriad peace-promoting government programs and third-party interventions in conflict and post-conflict settings, there is a limited understanding of how these efforts function (for reviews, see Blattman \& Ralston, 2015; Blattman \& Annan, 2016; Brük et al., 2016). With this article, we provide new insight into the relationship between developmental aid and conflict. To do so, we build on current disaggregated designs used to study local conflict dynamics (Cederman \& Vogt, 2017) and examine the effects of wartime aid projects on insurgent activity in the case of contemporary Afghanistan.

By analyzing data on the United States military's distribution of aid and its clashes with insurgents between 2004 and 2009 with a recently developed event-matching methodology, matched wake analysis (MWA) (Schutte \& Donnay, 2014), we uncover evidence linking aid-driven local exclusion and conflict. Specifically, we find that insurgent action increases soon after, and in the spatial vicinity of, the start of local-level aid projects that only benefit a small circle of residents, relative to projects helping the entire locality. When these results are interpreted in light of firsthand accounts from insecure areas of Afghanistan, they indicate that exclusionary local aid projects engender grievances associated with inequity and injustice, which then intensifies localized insurgent activity.

Corresponding author:

daniel.karell@nyu.edu 
The findings align with a growing body of scholarship showing that third-party aid programs reinforce indigenous perceptions of 'winners and losers', causing feelings of frustration among the losers (Tokdemir, 2017). Importantly, however, our micro-spatiotemporal design enables us to extend this insight to conflict dynamics at the local level. In addition, our results inform a debate over the efficacy of a large-scale aid program implemented by the US military, thereby sharpening our understanding of how local developmental aid can be used to stabilize regions wracked by war.

\section{Wartime aid and conflict}

As in other areas of social science, the study of war and peace has been guided by theories of human behavior. The predominant view in political economy and international relations research contends, first, that individuals facing the choice of engaging in armed conflict carefully relate the associated costs to the anticipated benefits and, second, that the payoffs of successful revolutions tend to apply to entire societies. Consequently, rebels face a collective action problem: fewer and fewer individuals would be willing to risk their lives for a political outcome that they could also live to see if they remained passive. Rebels should be inclined to 'free ride' on the efforts and sacrifices of their comrades. Thus, in this view, participation in conflict is non-economical and observed participation is likely best explained as an attempt to secure material benefits from the uprising (Olson, 1965; Lichbach, 1995).

This so-called 'rationalist' reasoning was bolstered as the widespread adoption of econometric methodology paved the road for global comparisons. A robust negative correlation between levels of economic development and conflict suggested that rebellion emerges only when rebels have nothing to lose (Collier \& Hoeffler, 2004). In addition, other factors contributing to civil war onset were found to correlate with lowered opportunity costs. Rebels operating against weak states and in inaccessible terrain, for example, appeared to face diminished risks compared to those attacking strong states (Fearon \& Laitin, 2003). Similarly, armed conflict was found to be more likely when foreign aid shocks rendered rebels' payoffs from conflict greater than what a government could credibly promise (Nielsen et al., 2011).

As a whole, this scholarship suggests that aid delivery should help decrease political violence - a belief long shared by policymakers and practitioners (Lake, 2010). One highly visible implementation of this conclusion was the US-led campaign to 'win hearts and minds' during the recent wars in Afghanistan and Iraq. Over the course of these conflicts, the US military introduced protocols to 'weaponize' aid (CALL, 2009) and lawmakers increased funding for local-level aid programs in conflict zones (Hedgpeth \& Cohen, 2008). Early research on these programs offered further support: aid in Iraq decreased insurgent activity (Berman, Shapiro \& Felter, 2011; Berman et al., 2013) and, in Afghanistan, increased the legitimacy of the state (Böhnke $\&$ Zürcher, 2013).

A growing body of empirical work, however, has begun to challenge the widespread assumption that aid generally mitigates violence. Nunn \& Qian (2014), for example, show that food aid to conflict zones increases the duration of conflict. Crost, Felter \& Johnston (2014) find that World Bank projects may stoke insurgent violence in the Philippines. Recent evidence from Afghanistan suggests that local-level aid projects instigated by US military units result in more attacks by armed opposition groups under certain conditions (Child, 2014; Beath, Christia \& Enikolopov, 2016; Sexton, 2016). A key insight from this recent scholarship is that insurgents strategically respond to types of aid, sometimes leading to an uptick in violence. Namely, insurgents resist the implementation of aid projects if the projects are of a type that jeopardizes their capacity to fight.

Empirical findings such as these draw our attention to how various types - rather than quantities - of aid function in precarious settings (e.g. Böhnke $\&$ Zürcher, 2013; Blattman \& Ralston, 2015). In this vein, we propose a way of understanding how aid affects conflict based on the influence projects can have on the intended recipients - the local populace. To do so, we build on the large body of research emphasizing that insurgencies are population-centric wars and, as a result, call for disaggregated approaches to studying conflict (see Cederman \& Vogt, 2017). In other words, we begin with the premise that incumbents and insurgents compete over the loyalties of citizens at the local level (e.g. Kalyvas, 2006; Lyall, 2009; Kocher, Pepinsky \& Kalyvas, 2011; Schutte, 2017). Adopting this perspective when systematically studying the effects of aid on intracommunity conflict dynamics, we believe, complements the extensive existing research focused on the rational and strategic calculus of armed actors. In the next section, we develop our framework by theorizing the differential effects of aid project types on relations within communities and popular support for anti-state actions. 


\section{Aid, exclusion, and violence}

Despite the prominence of rationalist explanations for conflict dynamics, some scholars of political violence and social movements have long pointed to feelings of frustration and injustice as an alternative (for a review, see Gurr, [1970] 2011). These so-called grievance-based explanations have seen a recent renaissance in comparative research. By disaggregating entire conflicts into actors such as rebel organizations and ethnic groups, the role of horizontal inequalities and political exclusion in fostering conflict has become more apparent (Buhaug, Cederman \& Rød, 2008; Wimmer, Cederman \& Min, 2009; Cederman, Gleditsch \& Buhaug, 2013; Wimmer, 2013). The rationalist explanations for armed conflict still hold by and large, but it has become clearer how specific circumstances systematically provoke grievances and increase the risk of conflict (Hechter, Pfaff \&Underwood, 2016).

We argue that such grievance can be induced by certain types of war-time aid. Certainly, some aid projects during wartime increase individuals' satisfaction with the incumbent and thereby foster peace. This is the operating assumption of incumbent military forces, international aid donors, and the rationalist-orientated scholars who argue that aid should decrease violence either by increasing the opportunity costs of joining the insurgency or compelling civilians to share actionable information on insurgents with the incumbent forces (Collier \& Hoeffler, 2004; Lebovic, 2010; Berman \& Matanock, 2015).

This assumption rests on the premise that aid projects benefit all members of a community somewhat equally. First-hand accounts from settings such as Afghanistan, however, provide ample evidence that local aid projects frequently favor one portion of the populace over others. Horne (2012), for example, details how well-connected civilian subcontractors can capture a large share of wartime aid to the detriment of the larger community. Chandrasekaran (2012: 169) reports that residents killed a district governor in Afghanistan's Helmand province because he was enriching himself from reconstruction projects rather than distributing resources more widely. Martin (2014: 112) recalls how Afghan villagers believed 'elders [responsible for overseeing aid projects] stole from their own communities', leading to his conclusion that 'these [aid project] dynamics fed jealousy in [...] society'.

While such evidence of inequity in aid benefits often centers on local government, tribal, or business elites (see Gordan, 2011; Gopal, 2014; Karell, 2015), the more general social process is rooted in feelings of 'rivalry', 'jealousy', 'injustice', and 'exclusion' (Fishstein \& Wilder, 2012). In other words, residents in fragile, unstable settings often interpret externally provided aid projects through the lens of a localized 'zero-sum' game. With each project, there are winners and losers, whether they are landed elites or marginalized citizens (Fishstein \& Wilder, 2012; Malkasian, 2013).

As with grievances fueled by horizontal inequalities between large subnational groups (Cederman, Gleditsch \& Buhaug, 2013), aid-induced exclusion can ultimately generate localized tensions and, sometimes, violence (e.g. Malkasian, 2013; Martin, 2014). ${ }^{1}$ This within-community dynamic occurs because the process unfolds among individual residents of a locality - a micro-pathway that is, in the end, not surprising. Beyond the anecdotal evidence from conflict settings, perceiving an inequitable distribution of payoffs has been systematically observed to be a potent motivator for levying punishment. This insight robustly emerges from lab and field applications of the 'ultimatum game' (Güth, Schmittberger \& Schwarze, 1982; Camerer \& Thaler, 1995). Tasked with dividing an allocated amount of resources between two players, the rational equilibrium strategy in this game is for the first player to reserve a maximum payoff for herself and offer a minimum to the other player. Correspondingly, the rational strategy for the second player is to accept any offer deviating from zero - a rejection by the second player, due to the rules of the game, would leave both players with nothing.

Yet, human behavior in this specific case drastically deviates from rationality. Second players receiving an offer they perceive as inequitable frequently reject it to punish the allocator even at the expense of their own payoff. In other words, punishment for an inequitable exclusion from resources has been found to routinely outweigh the costs. ${ }^{2}$ This discrepancy of rationalist expectation and behavioral reality has profound implications for developmental aid as a pacification strategy. If the benefits of incumbents' counterinsurgency aid projects favor only parts of the community, the perceived inequity of aid distribution may have an inadvertent adverse effect on civilian acceptance of government rule.

\footnotetext{
${ }^{1}$ As Fishstein \& Wilder (2012: 58) put it, 'If [ . . . ] some elements of society are perceived to have grown wealthy at the expense of others, this may feed a sense of injustice [...] that could motivate armed opposition [...] In this scenario, anger is bred not so much by absolute poverty but by a strong sense of exclusion and injustice.'

${ }^{2}$ For a review of the robustness of this pattern of behavior, see Henrich (2000) and Andersen et al. (2011).
} 
Namely, excluded civilians could reject incumbents' rule and begin supporting armed opposition as a way to 'punish' the incumbents. ${ }^{3}$

In sum, evidence from first-hand accounts, professionals in the field, and experimental social science suggests that in the midst of irregular wars, local-level exclusion from incumbent resource allocation can intensify subsequent insurgent activity. This relationship unfolds through an intracommunity micro-pathway linking aid, exclusion, grievances, and violence. Moreover, the evidence - and the micro-level dynamics indicate that the process commences with the initiation of aid projects. The start of a project provides a strong signal to residents regarding 'what is in [the project] for them' (Chandrasekaran, 2012: 72). This is because residents' perceptions of a project's scope and applicability perceptions that are quickly formed - influence their response to external aid (Böhnke \& Zürcher, 2013). Thus, based on these insights, we expect that the initiation of incumbent aid projects that exclude parts of the community will result in increased insurgent activity. ${ }^{4}$ The following section assesses this expectation through an analysis of the locations and timing of aid projects and insurgent activity.

\section{Empirical analysis}

\section{Case selection: Afghanistan}

As the recent US-led war in Afghanistan progressed, insurgent activity became more frequent and deadly. The USA and its allies responded with a strategic reconceptualization. Rather than encouraging peace by building democratic government institutions in Kabul, military forces were increasingly tasked with providing security and essential services to the populace via local-level aid projects (Lake, 2010). This aid was intended to gain the support of the populace and pacify the country - 'win hearts and minds'. Consequently, resources allocated to localized aid programs ballooned. For example, funding for the US military's 'Commander's Emergency

\footnotetext{
3 This argument assumes that the psychological reaction to inequity scales to violent conflict. This is based partly on the widely reported robustness of rejection behavior in circumstances when stakes are high (Henrich, 2000; Andersen et al., 2011). In addition, the assumption aligns with some of the foundational research on conflict motivation (Dollard et al., 1939; Gurr, [1970] 2011).

${ }^{4}$ Our focus on the initiation of projects is further motivated by recent evidence showing that the adverse effects of local aid programs on non-recipients are strongest at the start of the program, and that these negative effects dissipate quickly (Haushofer, Reisinger \& Shapiro, 2015).
}

Response Program' (CERP) in Afghanistan increased from 40 million USD in 2004 to one billion USD in 2010 (SIGAR, 2015).

Unfortunately, as discussed in the previous section, these 'hearts and minds' efforts did not benefit all members of local communities equally. In some instances, the inequity was unintended; resources were co-opted by local elites involved in project implementation (Fishstein \& Wilder, 2012; Horne, 2012). In other instances, however, inequitable benefits were part of projects' design. CERP projects, for example, ranged from supporting targeted marginalized segments of local communities (e.g. 'social protection' projects) to bolstering 'infrastructure and natural resources' accessible to all community residents, such as a new road or snow-clearing operations.

The contemporary Afghan conflict, then, offers an ideal opportunity for examining how external, localized wartime aid can have differential effects on insurgency activity, depending on how types of aid projects influence inequity and insurgent support among residents of communities. First, during this increasingly ferocious war, Afghans experienced an influx of aid projects into their communities that varied in excludability. Second, contemporary Afghanistan is what Gerring (2007) calls a crucial case: the amount of resources devoted to counterinsurgency-linked aid makes it a strong test of our argument. That is, in Afghanistan, observing a pacifying effect of aid is more likely. Therefore, if we see evidence of specific types of aid generating sympathy for insurgents and insurgent activity, we gain greater confidence in their detrimental effect.

\section{Aid provision and conflict dynamics}

In order to study the effects of aid-related local exclusion on subsequent conflict dynamics, we compare two types of aid projects with differing levels of accessibility: 'social protection' versus 'infrastructure and natural resources' CERP projects. Our comparison uses a recently developed methodology for the causal analysis of event data (Schutte \& Donnay, 2014). This allows us to test whether local aid projects' relative exclusivity leads to more insurgent activity in their vicinity after project initiation under otherwise most comparable conditions.

\section{Event data}

Our analysis primarily employs two datasets. The first covers 45,717 incidences of insurgent activity in Afghanistan from 2004 through 2009 gathered from the Significant Activity (SIGACT) database constructed by 
the US military. Using the SIGACT database rather than event data coded from media sources has three advantages. First, SIGACTs are passed up the chain of command from the platoon level, resulting in an extremely detailed record of the conflict. Second, SIGACT is free of the reporting biases and inaccuracies found in some media-based reporting (Weidmann, 2015, 2016). Third, SIGACT codes which side initiated an attack, enabling us to focus on insurgent activity. These advantages have contributed to a recent widespread use of SIGACT data (e.g. Braithwaite and Johnson, 2012; Condra \& Shapiro, 2012; Weidmann, 2015; Schutte, 2017).

Yet, despite the advantages, there remain two possible limitations. First, SIGACT data only capture events witnessed by US forces. Our focus, however, is on the influence of the US military's CERP projects, ensuring uniformly high probability of insurgent attacks being recorded in the data. Second, the data likely suffer from measurement error in that different units of US forces recorded events differently. But, as Berman, Shapiro \& Felter (2011) point out, there is no evidence that the error non-randomly varies with other variables of interest. Thus, due to its high precision and wealth of information, SIGACT is the ideal dataset for studying the dynamics of the Afghan insurgency.

The second dataset comprises records from NATO's Afghanistan Country Stability Picture (ACSP), a database on reconstruction and development projects across Afghanistan from 2003 to 2009 (Child, 2014). The dataset codes projects funded by CERP, an aid program corresponding to our interest in local-level conflict dynamics. CERP projects were implemented in collaboration with members of the local populace and were designed to have a relatively swift localized impact on civilians' attitudes and behaviors. Indeed, these attributes, which embody the ethos of contemporary counterinsurgency strategy, have resulted in several recent studies on the association between CERP and conflict (e.g. Berman et al., 2013; Child, 2014; Sexton, 2016). Unlike this previous work, however, we make use of the dataset's precise information on projects' start dates and geographic coordinates in a quasi-experimental design, as discussed below. We also make use of information on how each project has been categorized according to the Afghanistan National Development Strategy (GIROA, 2008), or ANDS, as well as a natural language description of what the project entailed.

\section{Types of aid}

We expect that the initiation of relatively more exclusionary aid will generate more insurgent activity. To examine this effect, we compare two types of CERP projects, 'social protection' and 'infrastructure and natural resources'. The projects classified under the former ANDS label provided targeted assistance to marginalized segments of communities by delivering cash or material to individuals deemed vulnerable, either directly or through local contractors and nongovernmental organizations (GIROA, 2008). Consequently, social protection projects benefited only portions of communities, either by singling out residents for special help or funding private local groups. In contrast, infrastructure projects had a more inclusive aim. They comprised activities such as the building and maintenance of roads and the development of electrical and telecommunications grids (GIROA, 2008). Between 2003 and 2009, the range of our data, there were 1,142 social protection projects and 1,482 infrastructure projects.

We maintain that social protection projects were more exclusive than infrastructure efforts. ${ }^{5}$ This argument is based on published interviews with Afghans and research showing that rural residents consistently understood aid as exclusionary when some individuals benefited from directly receiving or capturing resources, not when development improved living conditions for some but not others (Fishstein \& Wilder, 2012; Karell, 2017). In addition, residents regularly stated a desire for infrastructure projects, which they described as providing broad benefits. Finally, when infrastructure projects were reported to be exclusionary, it was often between - not within - broader settlement areas, such as when a bridge connected one community but not another to a district center (Gordan, 2011; Fishstein, 2012; Fishstein \& Wilder, 2012). Such a potential source of tension operates at a different scale than our following micro-spatiotemporal analysis; our design uncovers distinct conflict dynamics at a within-community scale (e.g. $2 \mathrm{~km}$ ).

A possible objection to using ANDS labels for project classification is that the labels might not reflect the actual activity. So, to gain more insight into what types of projects entailed, we analyze individual projects' natural language descriptions using latent Dirichlet allocation (LDA) topic models (Blei, $\mathrm{Ng} \&$ Jordan, 2003). These models probabilistically identify 'topics', inferred from words' co-occurrence, across the individual project

\footnotetext{
${ }^{5}$ We cannot rule out that some infrastructure projects offered exclusive benefits: a new irrigation canal could have helped a portion of a community's farmers but not others. However, we posit that, overall, infrastructure aid acted as less exclusionary within communities than social protection aid.
} 
Table I. Topics by project category

\begin{tabular}{|c|c|c|}
\hline Topic & Social protection & $\begin{array}{l}\text { Infrastructure and } \\
\text { natural resources }\end{array}$ \\
\hline 1 & $\begin{array}{l}0.05 \\
\text { equip, cook, facilit, } \\
\text { tarp, tool, one }\end{array}$ & $\begin{array}{l}0.38 \\
\text { villag, district, well repair, } \\
\text { bridge, pave }\end{array}$ \\
\hline 2 & $\begin{array}{l}0.08 \\
\text { paint, current, stock, } \\
\text { replac, tent, blanket }\end{array}$ & $\begin{array}{c}0.43 \\
\text { road, provid, water, } \\
\text { construct, well, power }\end{array}$ \\
\hline 3 & $\begin{array}{c}0.06 \\
\text { day, rug, citizen, general, } \\
\text { instal, valley }\end{array}$ & $\begin{array}{c}0.07 \\
\text { sourc, generat, locat mhp, } \\
\text { clinic, along }\end{array}$ \\
\hline 4 & $\begin{array}{c}0.74 \\
\text { assist, silo, replenish, } \\
\text { provid, materi, } \\
\text { humanitarian }\end{array}$ & $\begin{array}{l}0.07 \\
\text { contract, construct, } \\
\text { retain, lead, power, twa }\end{array}$ \\
\hline 5 & $\begin{array}{c}0.06 \\
\text { aid, request, pump, tea, } \\
\text { bag, transport }\end{array}$ & $\begin{array}{c}0.05 \\
\text { citizen, facil, dari, } \\
\text { signific, trash, benefit }\end{array}$ \\
\hline
\end{tabular}

The table shows the six words most associated with each topic and the distribution of the topic in each project type corpus. Words have been stemmed.

descriptions included under the labels of 'social protection' and 'infrastructure and natural resources'. In simpler terms, the topic models help us evaluate whether the descriptions reflect their project's categorized type, without pre-analysis biases (Mohr \& Bogdanov, 2013).

We gather the descriptions under each of the two project types into separate corpora, then model five topics for each collection. ${ }^{6}$ Table I presents the six words most associated with each topic, as well as the distribution of these topics in each corpus. We see that the topics evoke their respective ANDS label. The most prevalent social protection topic (Topic 4) concerns replenishing and providing humanitarian material. Other topics allude to the provision of goods to needy recipients, such as cooking facilities and equipment (Topic 1) and tents and blankets (Topic 2). The topics generated by the infrastructure project descriptions are suggestive of, unsurprisingly, infrastructure. The two most common topics relate to repairing bridges and pavement (Topic 1) and providing or constructing roads, wells, water, and power (Topic 2).

\footnotetext{
${ }^{6}$ Online appendix A provides details on the two corpora and the topic modeling procedures.
}

The topic modeling supports, first, the validity of using ANDS labels to differentiate project types and, second, our interpretation of the projects' relative exclusivity. The social protection project descriptions indicate that these projects benefited specific segments of the population, such as those in need of immediate humanitarian assistance. In contrast, the topics found in the infrastructure and natural resources project descriptions show that these projects supported widely accessible development. However, to be clear, we do not conceptualize social protection projects or infrastructure works as being universally exclusive or inclusive, respectively. Infrastructure projects could have benefited limited portions of a community, such as contractors awarded a construction bid or residents living nearest to a new bridge crossing. Instead, we understand these project types as proxying the ends of an ordinal range of aid exclusivity.

\section{Matching variables}

With both the CERP and SIGACT data, each observation corresponds to one event of an aid project or insurgent incident, respectively, with precise geographic coordinates and dates. To account for possible confounding factors that could predict both the type of project implemented and the level of insurgent activity, we superimpose CERP and SIGACT events with geographic context information from multiple sources. As explained in the methodological section below, these spatiotemporal variables are used in the inferential analysis.

The selection of variables is guided by insights into the micro-dynamics of violence in civil wars. First, several studies point to the importance of inaccessible terrain for providing shelter for insurgents (e.g. McColl, 1969; Fearon \& Laitin, 2003; Buhaug, Gates \& Lujala, 2009) and the correlation between population and number of conflict events (Raleigh \& Hegre, 2009). To account for these effects, we used spatially referenced data on elevation above sea level (Gesch, Verdin \& Greenlee, 1999), with an approximate resolution of $1 \mathrm{~km}$ close to the equator to assign the elevation of each geographic point, population size, and whether an event occurred in an urban or non-urban environment. ${ }^{7}$

\footnotetext{
${ }^{7}$ Data on population are from the Gridded Population of the World database (http://sedac.ciesin.columbia.edu/data/collection/gpw-v3/ sets/browse). An urban environment is defined as an area within a $10 \mathrm{~km}$ radius of the geographic center of each city with a population of 100,000 or over. Urban data are from the Afghanistan Central Statistics Office (http://cso.gov.af/).
} 


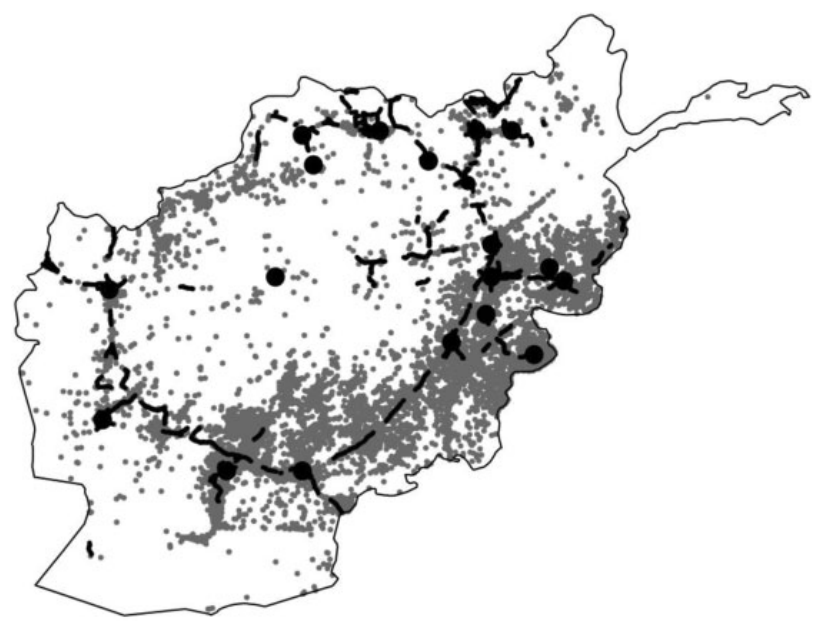

Figure 1. Map of Afghanistan showing all insurgent events in SIGACT, cities, and major roads

Insurgent events (2004-09) are depicted as gray dots; black dots are major cities; and main roads are dashed lines. The events cluster close to these roads.

In Afghanistan, conflict events also correlate with the presence of roads since most violent incidences were improvised explosive devices (IEDs) planted alongside roads to target incumbent vehicles (Figure 1). Conflict events also correlate with areas dominated by members of the Pashtun ethnic group, but less so Hazara areas, where the predominant ethnic group has largely supported the government and its Western allies. Therefore, we also code whether the event occurred within $5 \mathrm{~km}$ of a road, whether the majority of residents are of Pashtun ethnicity or not, and whether the majority of residents are of Hazara ethnicity or not. ${ }^{8}$

Finally, we include two attributes of the CERP projects beyond their type: duration and cost. These two characteristics indicate each project's size. Previous analyses of CERP data have found that project size affects its effectiveness - smaller projects are understood to be better tailored to local needs, thus making them more likely to improve living conditions and mitigate violence (Berman et al., 2013). ${ }^{9}$ Table II provides a summary

\footnotetext{
${ }^{8}$ Road data were collected from the Afghanistan Information Management Services (http://www.aims.org.af/); ethnicity data are from the GeoEPR dataset (Wucherpfennig et al., 2011).

${ }^{9}$ We do not match on measures of inequality or poverty because any effect of pre-existing inequality on insurgency would be captured in the measured trends of pre-treatment insurgent violence (see Nepal, Bohara \& Gawande, 2011; Blattman \& Annan, 2016). Furthermore, we do not match on incidences of aid being delivered by the major alternative program implemented at the time, the National Solidarity Program (NSP) (Beath, Christia \& Enikolopov, 2013). The reason is
}

Table II. Summary statistics of spatiotemporal variables

\begin{tabular}{lc}
\hline & CERP projects \\
\hline In rural area & $82.5 \%$ \\
At mean elevation (meters) & 1,615 \\
Within $5 \mathrm{~km}$ of road & $95.11 \%$ \\
Mean population & 4,242 \\
In Pashtun area & $60.12 \%$ \\
In Hazara area & $4.12 \%$ \\
Median cost (USD) & 35,000 \\
Median duration (days) & 61 \\
\hline
\end{tabular}

of how these spatiotemporal variables are distributed across CERP events. Appendix B, in the Online appendix, shows that these matching variables correlate with project types and levels of violence.

\section{Method}

In order to test the argument that social protection projects will lead to relatively more insurgent activity than infrastructure projects, we perform a matched wake analysis, or MWA (Schutte \& Donnay, 2014). MWA identifies natural experiments in precise spatiotemporal data by performing four steps. First, events are divided into one of three categories: 'treatment', 'control', and 'dependent'. Treatment and control events are compared against one another. In this case, the two types of CERP projects are compared. The dependent events are used to measure the effect of the treatment and control events; their frequency is posited to be affected by these events. As explained above, dependent events in this case are all records in SIGACT coded as 'insurgent activity'.

Clearly, aid projects are not singular events, but rather protracted episodes of civilian-military collaboration. However, we analyze aid projects as events based on their start dates. As discussed earlier, residents react to aid distribution once the manner of resource provision is announced via project initiation. In other words, project

that, as Böhnke \& Zürcher (2013: 420) note, the NSP was a massive program with a relatively even spatial spread. It was designed to deliver aid to as many communities as possible, and most Afghan communities participated. Indeed, a nationally representative survey of Afghans shows that a majority of Afghans lived in a community with an NSP project (Warren, 2014). Finally, following the recommendation of a reviewer, we consider the effect of US troop presence, as done in Sexton (2016). We include these data in a supplementary analysis, found in Online appendix D, rather than the main analysis because the observations of troop presence only begin during 2008 - four years after our own event dataset. 
initiation is an opportune time to study responses to what CERP projects signal to the community.

In a second step, MWA establishes counts of treatment, control, and dependent events temporally prior and posterior to all treatment and control events. For this count, only events within certain spatial and temporal distances are taken into account, for example, within up to five days before and after the event and up to $5 \mathrm{~km}$ away from the actual CERP project site and date of implementation. The counts of preceding events serve as matching variables in the subsequent step.

In a third step, MWA uses a matching algorithm, coarsened exact matching (Iacus, King \& Porro, 2012), or CEM, to build samples of treatment and control events under otherwise most comparable conditions. Matching variables include the trend in preceding dependent events, counts of preceding treatment and control events, and the spatial context information and event characteristics discussed in the preceding section. ${ }^{10}$ Constructing these matched samples paves the way for studying the effects of 'treatment' events in isolation of confounding contextual factors. This way, the matching step helps identify natural experiments in event data: changes in subsequent dependent events are calculated under otherwise most comparable conditions. ${ }^{11}$ Treatment effects are estimated with a difference-indifferences regression design (Angrist \& Pischke, 2009)

\footnotetext{
${ }^{10}$ Matching on counts of preceding treatment and control events is suggested by Schutte \& Donnay (2014) to remedy a limitation of this empirical strategy. Events of interest, such as newly started aid projects, can occur in close spatial and temporal proximity to one another. This entails a violation of a central assumption of causal identification: identical treatments across observations. One would risk comparing the effect of one type of project with the combined effect of two different types of projects that occurred in close spatial and temporal proximity. To mitigate this, matching on previous counts of treatment and control events ensures that, for instance, control events that were preceded by one treatment event are compared to treatment events that were preceded by one treatment event. We adopt this approach in our analysis and report percentages of overlapping events in Table III.

${ }^{11}$ MWA aims to solve the identification challenge by matching on trends of violence and relevant variables. To the extent that this strategy does not fully account for selection, we must assume that the implementation of CERP project types was not primarily driven by preceding violent events. This assumption is supported by the limited research on project selection. Adams (2015) uses interviews with US military officers utilizing CERP funds in Afghanistan to report that the officers selected projects based on 'local [civilian] needs' and 'mobilizing local governance'. Moreover, none of the respondents believed that CERP projects improved stability. That is, the projects were not seen as viable responses to previous insurgent violence.
}

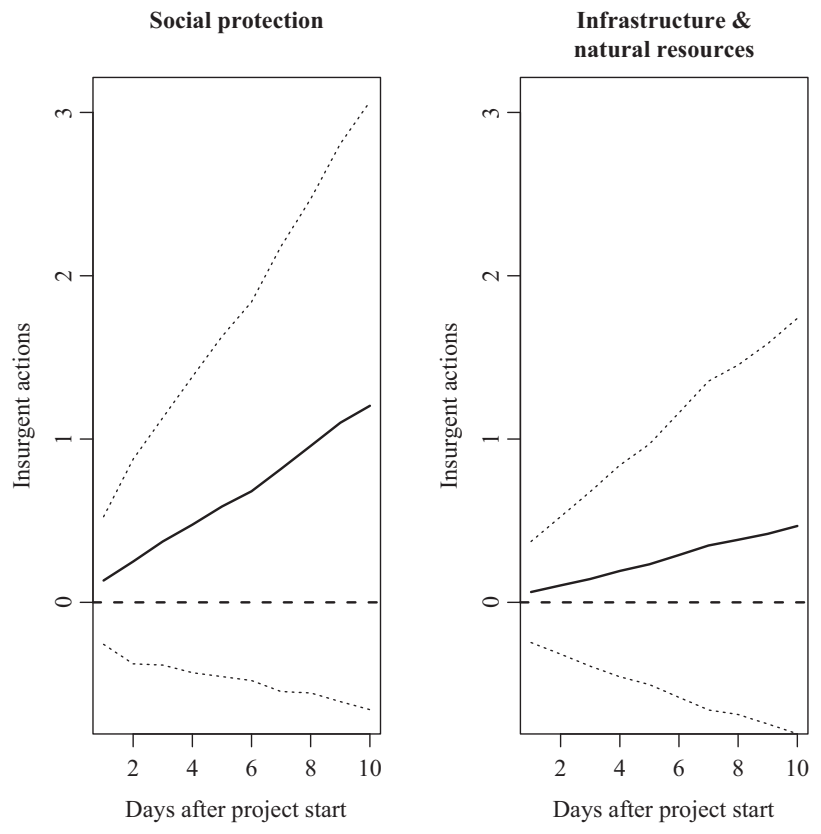

Figure 2. Average counts of insurgent activity after project initiation

The solid lines show average counts of insurgent activity for over time, beginning with project initiation. Events occurred within two $\mathrm{km}$ of the project site. Dashed lines correspond to one standard deviation in counts.

that estimates the number of posterior events as a function of previous events and the binary treatment indicator (Equation 1):

$$
n_{\text {post }}=\beta_{0}+\beta_{1} n_{\text {pre }}+\beta_{2} \text { treatment }+u .
$$

Finally, by systematically varying the temporal and spatial distances around CERP sites, the robustness of any substantive effect for different spatial and temporal aggregations can be assessed. An illustration of the inner workings of the method can be found in Online appendix C.

\section{Results}

Initial insights into the effects of different CERP projects on subsequent conflict dynamics can be obtained descriptively. Focusing on the intensity of conflict dynamics at a local level $-2 \mathrm{~km}$ aggregations - and ignoring previous trends, Figure 2 shows counts and standard deviations of insurgent activity for different project types. Two effects are apparent in this simple analysis. First, social protection CERP projects are on average associated with more subsequent insurgent activity than infrastructure projects. This observation is in line with the theoretical expectation. However, it does 
not qualify as a full test of the theory as possibly confounding conditions and preceding trends are ignored. A second noteworthy aspect is the linear increase in insurgent activity after project initiation. A linear trend suggests that post-initiation conflict dynamics do not systematically escalate in cycles of attacks and counter-attacks, which would have imperiled causal identification.

As a first inferential test of our theoretical expectations, we conduct a simplified MWA; none of the contextual variables are included in the matching process. This establishes the basic effects of social protection versus infrastructure aid projects on subsequent insurgent activity for multiple spatial and temporal levels of aggregation. Specifically, we examine changes in insurgent activity for aggregations ranging from $2 \mathrm{~km}$ to $10 \mathrm{~km}$ from the CERP project site and temporal aggregations from two to 20 days after the project started. Our theoretical framework focuses our attention on intracommunity conflict dynamics captured in small aggregations - $2 \mathrm{~km}$ to $4 \mathrm{~km}$, for example - but the substantive results also hold for larger scales. ${ }^{12}$ As discussed earlier, we begin the MWA comparisons with the initiation of projects. The start of a project signals to the community what type of aid is being implemented, which then triggers assessments of exclusion and subsequent grievances (Chandrasekaran, 2012; Böhnke \& Zürcher, 2013; Malkasian, 2013; Martin, 2014).

In this first baseline test, we find support for our argument. When matching only on the preceding trend of insurgent activity, insurgent actions following relatively exclusive social protection projects increase in comparison to infrastructure projects. Figure 3 depicts estimated effects at various levels of aggregation as a contour plot. Clear areas correspond to significant results for the estimated treatment effect at the 0.05 level. We see that the estimated effect of social protection projects, relative to infrastructure projects, peaks at around 0.45 for larger aggregations.

\footnotetext{
${ }^{12}$ Spatial aggregations smaller than $2 \mathrm{~km}$ would very likely not generate meaningful insights because there are few insurgent events that almost exactly coincide spatially (or temporally) with projects. Analyzing larger spatial and temporal aggregations than $10 \mathrm{~km}$ and 20 days would be substantively interesting, but this is empirically not feasible based on the chosen design. Larger spatial and temporal aggregations of 100 days and $100 \mathrm{~km}$, for example, would contain too many overlapping events: we would be unable to differentiate the effects of different projects on overall levels of insurgent activity. For a more technical discussion of this problem and possible remedies see Schutte \& Donnay (2014).
}

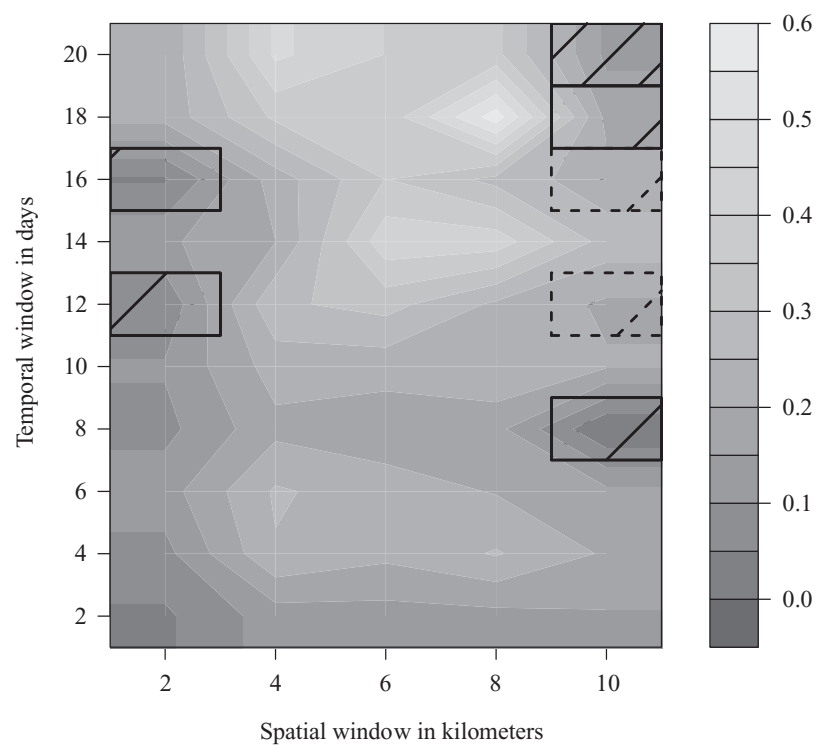

Figure 3. Effect of exclusive aid projects on insurgent activity without matching on spatiotemporal variables

In the clear areas, the estimate is significant at the $p<0.05$ level. In areas covered by dashed cross-hatching, it is significant at $p<0.1$. In areas with solid cross-hatching the estimate is not significant. Estimates are predominantly positive at all considered levels of aggregation.

In the direct proximity of aid projects (i.e. $2 \mathrm{~km}$ aggregations), we find effects ranging from 0.1 to 0.2 for different temporal windows. This suggests that, at the local level, one out of five social protection projects causes an incident of insurgent activity, compared to infrastructure projects. Remarkably, the results are very robust to changes in the temporal and spatial aggregations and appear positive and significant for most areas of the plot. Thus, this first analysis offers evidence for a robust positive effect of relatively exclusive CERP projects on the trend of insurgent activity.

Up to this point, however, the analysis is agnostic to the possible effects of confounding contextual factors. It could be that the two types of projects are implemented under systematically different circumstances that could also cause different levels of subsequent violence. To address this, we conduct a second analysis that includes the spatiotemporal variables in the matching of observations. We now observe the effects of different types of aid projects under otherwise comparable circumstances. ${ }^{13}$

\footnotetext{
${ }^{13}$ Another possible approach would entail modeling the effects of the introduced variables in a multivariate regression model. This would require explicit choices for the functional forms of the proposed relationships between independent and dependent variables. For
} 


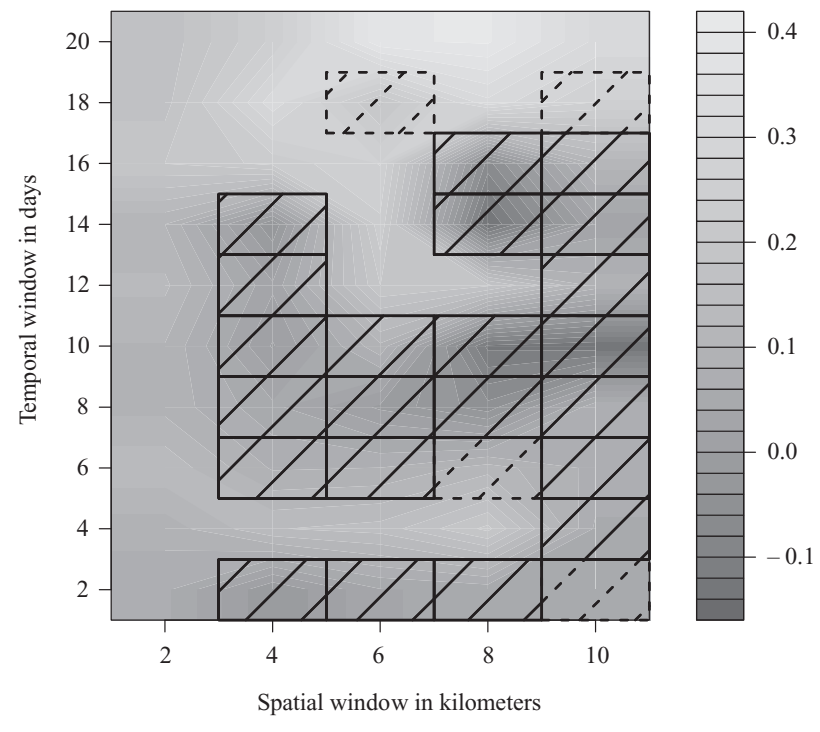

Figure 4. Effect of exclusive aid projects on insurgent activity with matching on spatiotemporal variables

Matching done on population size, elevation, road proximity, urban proximity, Pashtun region, Hazara region, project cost, and project duration. See Figure 3 note for interpretation of plot.

How do the results change once population levels, elevation, information on the predominant ethnic group at the project site, road proximity, urban proximity, and the cost and duration of the project are taken into account? As Figure 4 shows, the estimated effects of social protection projects are still largely positive. For the aggregation level we interpret as most indicative of intracommunity dynamics, $2 \mathrm{~km}$, the results remain substantively similar as the baseline test across temporal aggregations. In other words, the introduction of relatively exclusive CERP projects continues to cause an increase in subsequent insurgent activity at the local level, compared to the implementation of a more inclusive infrastructure project. ${ }^{14}$ The effect remains positive for larger spatial aggregations, although mostly not significant. This broader non-significance at bigger spatial aggregations underscores the local nature of identified conflict dynamics.

such an analysis, these choices would have to be justified for all spatial and temporal levels of aggregation. In contrast, our matching approach allows us to remain agnostic to functional forms and automated matching ensures that balance improvements are achieved for all levels of aggregation.

${ }^{14}$ We arrive at similar results in a supplementary analysis that matches on the presence of US soldiers (Online appendix D).
While Figure 3 and Figure 4 communicate the main findings of the analysis at one glance, additional information and detailed results can be found in Table III. Beyond the estimated effects, the most important insight communicated in this table is that matching improves the empirical sample: the similarity of social protection and infrastructure projects in the sample increases as a function of the introduced matching variables. These improvements are communicated through a measure of multivariate similarity, the percentage of 'common support' (\%CS). ${ }^{15}$ Common support increases at about three to five percentage points in the interpreted areas, indicating that the overlap of the joint distributions of the matching variables between treatment and control group improved. ${ }^{16}$

Returning to the substantive discussion of the results, estimates that are all positive and largely robust to changes in spatial and temporal aggregations align with first-hand accounts from Afghanistan's conflict zones and our theoretical expectation. In sum, they provide support for our argument: third-party aid projects that empower, enrich, or benefit a specific and limited segment of a local population - even if the beneficiaries are marginalized residents - result in greater subsequent insurgent activity, relative to comparatively inclusive aid projects.

\section{Discussion}

Our findings indicate that local aid projects, such as those widely used to 'win hearts and minds' in Afghanistan and Iraq, can be both a source of contentment and contestation, depending on their exclusivity. This conclusion fits with key insights from first-hand accounts of wartime development efforts (e.g. Fishstein \& Wilder, 2012; Malkasian, 2013), behavioral economics (e.g. Güth, Schmittberger \& Schwarze, 1982; Camerer \& Thaler, 1995), and a recent renaissance of grievancebased explanations for the onset of high-risk collective action in ethnic civil war (e.g. Buhaug, Cederman \& Rød, 2008; Cederman, Gleditsch \& Buhaug, 2013; Wimmer, 2013). Our analysis contributes to this body of scholarship by examining similar dynamics of exclusion and conflict, first, across the entirety of

${ }^{15}$ Iacus, King \& Porro (2012) introduce common support as a measure for the ranges of variable values jointly represented in both groups.

${ }^{16}$ However, small but persistent levels of spatiotemporal overlaps of observations suggest the results should be interpreted cautiously (Schutte \& Donnay, 2014). 
Table III. Detailed MWA results

\begin{tabular}{|c|c|c|c|c|c|c|c|c|c|c|c|c|c|c|}
\hline \multicolumn{5}{|c|}{ Results } & \multicolumn{5}{|c|}{ Before matching } & \multicolumn{5}{|c|}{ After matching } \\
\hline & Time & Space & Est. & $p$ & $N$ & $\%$ Treat. & $\% C S$ & $\% S O$ & $\% M O$ & $N$ & \%Treat. & $\% C S$ & $\% S O$ & $\% M O$ \\
\hline 1 & 2 & 2 & 0.07 & 0.00 & 2,607 & 40.00 & 14.10 & 27.80 & 3.90 & 1,909 & 40.00 & 18.70 & 30.50 & 5.40 \\
\hline 2 & 4 & 2 & 0.09 & 0.00 & 607 & 35.40 & 13.40 & 30.00 & 4.50 & 1,753 & 35.40 & 19.00 & 33.50 & 7.90 \\
\hline 3 & 4 & 4 & 0.14 & 0.00 & 2,607 & 39.30 & 12.20 & 32.50 & 6.40 & 836 & 39.30 & 17.00 & 36.80 & 11.00 \\
\hline 4 & 4 & 6 & 0.15 & 0.00 & 2,60 & 39.80 & 11.60 & 34.40 & 7.70 & 1,766 & 39.80 & 16.00 & 39.40 & 12.50 \\
\hline 5 & 4 & 8 & 0.21 & 0.00 & 2,6 & 42.0 & & 36. & & & 42.00 & & 42.00 & 13.50 \\
\hline 6 & 6 & 2 & 0.14 & 0.00 & 2,6 & 38. & 12. & 31.50 & & & 3.10 & & 10 & 8.90 \\
\hline 7 & 8 & 2 & 0.09 & 0.00 & 2,60 & 34.50 & 11.40 & 32.70 & 5.70 & 1,68 & 34.50 & 16. & 36.30 & 9.90 \\
\hline 8 & 10 & 2 & 0.10 & 0.01 & 2,60 & 32. & & 33.80 & 6.20 & 1 & & & 90 & 10.80 \\
\hline & 12 & 2 & 0.12 & 0.00 & 2,60 & & & & 6.70 & & & & & 12.00 \\
\hline 10 & 12 & 6 & 0.20 & 0.01 & 2,60 & 34. & & 40.40 & & & & & & 19.70 \\
\hline 11 & 12 & 8 & 0.18 & 0.05 & 2,607 & 37.40 & 10.20 & 43.30 & 13.00 & & 37.40 & & 50.60 & 21.70 \\
\hline 12 & 14 & 2 & 0.10 & 0.02 & 2,607 & & & 35.80 & 8.00 & & & & & 13.80 \\
\hline 13 & 14 & 6 & 0.2 & 0.0 & & & & & 13.80 & & & & & 22.60 \\
\hline 14 & 16 & 2 & 0.20 & 0.0 & 2,6 & & & & & & & & 41.90 & 16.00 \\
\hline 15 & 16 & 4 & 0.23 & 0.0 & 2,6 & 35.20 & 11.10 & 40.80 & 13.30 & 2 & 35.20 & & 47.60 & 21.90 \\
\hline 16 & 16 & 6 & 0.26 & 0.0 & 2,607 & 34.00 & 10.30 & 43.80 & 15.80 & 5 & 34.00 & 11. & 52.00 & 25.00 \\
\hline 17 & 18 & 2 & 0.17 & 0.0 & 2,607 & 32.00 & & 37.30 & 10.20 & 1,667 & 32.00 & 13.00 & 42.70 & 17.50 \\
\hline 18 & 18 & 4 & 0.31 & 0.00 & 2,607 & 31.70 & 10.00 & 41.50 & 14.10 & 1,660 & 31.70 & 12.30 & 48.50 & 23.70 \\
\hline 19 & 18 & 8 & 0.31 & 0.02 & 2,607 & 33.30 & 8.30 & 47.90 & 18.30 & 1,527 & 33.30 & 9.40 & 56.70 & 29.50 \\
\hline 20 & 20 & 2 & 0.17 & 0.00 & 2,607 & 32.50 & 11.00 & 37.90 & 10.70 & 1,704 & 32.50 & 12.20 & 43.50 & 18.80 \\
\hline 21 & 20 & 4 & 0.24 & 0.01 & 2,607 & 31.20 & & 42.40 & 14.80 & 1,645 & 31.20 & 11.50 & 49.40 & 25.20 \\
\hline 22 & 20 & 6 & 0.40 & 0.0 & 2,607 & 34.50 & & 45.50 & & 1,684 & & & 53.90 & 28.90 \\
\hline 23 & 20 & 8 & 0.40 & 0.0 & & & & & & & & & 57.50 & 31.60 \\
\hline 24 & 20 & 10 & 0.32 & 0.04 & 2,607 & 34.70 & 7.00 & 52.00 & 24.70 & 1,580 & 34.70 & 6.50 & 61.60 & 35.80 \\
\hline
\end{tabular}

This table presents detailed MWA results based on all matching variables. Matching always increases common support (\%CS). Overlapping events (the 'SO' and 'MO' columns) peak at about 30\% for the interpreted areas of the plot. These levels of overlap are not prohibitively large. See Schutte \& Donnay (2014) for a corresponding discussion.

Afghanistan over several years and, second, at the local and event levels.

Development aid can, of course, spur insurgent violence in other ways. Two prominent arguments predation and territorial loss - emphasize insurgents' violent reaction to aid programs. These insurgentcentered explanations and our argument are not mutually exclusive; specific outbursts of violence can have distinct causes. Yet, our findings provide stronger support for the dynamics of exclusion rather than alternatives. Namely, if violence was driven by insurgents trying to capture resources, as the predation scholarship argues (Grossman, 1991), then attacks should have increased after infrastructure projects. These projects offered more valuable contestable material - for example, construction equipment versus blankets delivered by social protection projects and a greater increase in the revenue of localities available for extortion by insurgents (Dube \& Vargas, 2013). Similarly, we should have also observed infrastructure projects increase violence if insurgents were responding to territorial loss: a larger portion of the population would have benefited from infrastructure projects, leading to more information being shared, resulting in more territorial loss, and, eventually, more violence (Weintraub, 2016). In sum, while alternative processes of insurgent reaction and civilians' rational calculus are bound to influence conflict in some settings, our analysis underscores how intracommunity social exclusion shapes conflict.

\section{Limitations}

Our study is not without limitations. Chief among these is that we cannot distinguish among the specific micromechanisms that link grievances and support or participation for violence. This process may be driven by a superficial instrumental reaction - say, attacking a rival - or resentment over an inequitable distribution of resources. Nevertheless, the crucial insight is the same: exclusion, generated inadvertently by aid provision, can 
trigger a process among individuals and within communities that ends in political violence.

Three other limitations are more technical. First, the MWA procedure permits analyses only at aggregations of a few days and several kilometers; larger spatiotemporal windows contain too many overlapping events. As a result, our study provides insights on immediate-term conflict dynamics, although, as we have discussed, there are sound theoretical reasons to do so. Future research, described in more detail below, could extend the analysis to projects' lifetimes and bridge our findings to medium-term conflict dynamics. Second, while we have carefully selected our matching variables and observe balance improvements, we acknowledge the possibility of not achieving sufficient balance on unobserved factors.

Third, we do not compare CERP projects to other aid programs operating in Afghanistan. This decision is based partly on the fact that the major alternative program, the NSP, was roughly evenly distributed across the country (Böhnke \& Zürcher, 2013). However, there is also a methodological consideration: comparing CERP projects to projects in other programs would entail an assumption of stable treatment effects across very differently designed programmatic aid efforts. Thus far, the literature is largely silent on the validity of such an assumption.

\section{Future research}

Despite these limitations, we have confidence in our study's insights due to the alignment between our empirical findings and both the rich qualitative secondary literature and recent theoretical advances. Indeed, we see the study's limitations as pointing to important areas for future research.

The first two directly address our technical limitations. Further research is needed to compare the various different aid programs - not just types of aid - that are launched in conflict and post-conflict settings. Such comparisons are becoming increasingly common (e.g. Blattman \& Ralston, 2015), but have been lacking in much of the extant scholarship. A second area for future work would be to link our findings regarding the immediate term with impacts at medium-temporal ranges (Cederman \& Vogt, 2017). In fact, our findings have direct implications for medium-range conflict dynamics. Namely, if locally delivered aid divides communities into multiple aggrieved, anti-state factions, the increasing fracturization can independently further intensify conflict (Metternich et al., 2013).
A third area for future work would bridge our findings of aid's negative impact on conflict at the local level (and similar findings at subnational levels in, for example, Crost, Felter \& Johnston, 2014; Beath, Christia \& Enikolopov, 2016; Sexton, 2016) with the large literature at the macro level that finds a pacifying effect of aid (e.g. Nielsen et al., 2011; Savun \& Tirone, 2011; Gutting \& Steinwand, 2017). Of course, this latter scholarship often analyzes bilateral aid disbursements, pools together various types of aid (e.g. aid to government institutions, aid to civil society groups, aid for infrastructure and development), and does not explicitly differentiate between local- and national-level projects, but, nevertheless, the contradictory findings allude to potentially fruitful discovery. One starting point may be Böhnke \& Zürcher's (2013) intriguing finding that local aid bolsters the state's legitimacy among the populace. Perhaps aid causes immediate-term violent reactions while more slowly cultivating state legitimacy, resulting in a longterm pacifying effect.

\section{Conclusion}

By developing a local-level, population-centric argument for how third-party wartime aid influences conflict dynamics and analyzing events using recently developed quasi-experimental methods for spatiotemporal data, we find that aid projects affect local conflict in systematically different ways. Relatively exclusive aid, proxied by social protection CERP projects, has a robust positive effect on subsequent insurgent activity, compared to relatively inclusive projects. These findings extend a growing body of literature on grievance-based explanations for conflict dynamics to the more micro levels of the locality and individuals.

Importantly, in the case of Afghanistan, we show that such effects are an inadvertent result of incumbents' attempts to mitigate insurgency. We thus offer a theoretically driven and empirically based answer to the current debate on the efficacy of counterinsurgency practices, such as CERP projects. Our answer points to the careful consideration that must accompany the use of developmental aid as a policy instrument for reducing violence and insecurity during ongoing irregular conflicts. Put in a different way, our study's insights not only shed light on how conflict can fuel further conflict, but also serve as a reminder that well-intentioned aid projects can have adverse effects when they exclude non-recipients. Taking these adverse effects into account for the design of humanitarian projects and stabilizing missions seems advisable in the light of the presented evidence. 


\section{Replication data}

The dataset and code scripts for the empirical analysis in this article, as well as the Online appendix, can be found at http://www.prio.org/jpr/datasets.

\section{Acknowledgments}

The authors would like to thank Travers Child, Brandon Gorman, Charles Kurzman, and Abdul Noury. We are also indebted to Richard Morgan, Steven Pfaff, Katherine Stovel, Andreas Wimmer, and three anonymous reviewers for their excellent comments on later versions.

\section{Funding}

Research for this project was supported by the EU FP7 Marie Curie Zukunftskolleg Incoming Fellowship Program (Grant no. 291784), held by Sebastian Schutte, and Daniel Karell's appointment as a Fung Global Fellow at Princeton University.

\section{References}

Adams, Greg (2015) Honing the proper edge: CERP and the two-sided potential of military-led development in Afghanistan. Economics of Peace and Security 10(2): 53-60.

Andersen, Steffen; Seda Ertac, Uri Gneezy, Moshe Hoffman \& John List (2011) Stakes matter in ultimatum games. American Economic Review 101(7): 3427-3439.

Angrist, Joshua \& Jörn-Steffen Pischke (2009) Mostly Harmless Econometrics. Princeton, NJ: Princeton University Press.

Beath, Andrew; Fontini Christia \& Ruben Enikolopov (2013) Empowering women through development aid: Evidence from a field experiment in Afghanistan. American Political Science Review 107(3): 540-557.

Beath, Andrew; Fontini Christia \& Ruben Enikolopov (2016) Winning hearts and minds through development: Evidence from a field experience in Afghanistan. MIT Political Science Department research paper no. 2011-14 (https://ssrn. com/abstract $=1809677)$.

Berman, Eli \& Aila Matanock (2015) The empiricists' insurgency. Annual Review of Political Science 18: 443-464.

Berman, Eli; Joseph Felter, Jacob Shapiro \& Erin Troland (2013) Modest, secure, and informed: Successful development in conflict zones. American Economic Review: Papers \& Proceedings 103(3): 512-517.

Berman, Eli; Jacob Shapiro \& Joseph Felter (2011) Can hearts and minds be bought? The economics of counterinsurgency in Iraq. Journal of Political Economy 119(4): 766-819.

Blattman, Christopher \& Jeannie Annan (2016) Can employment reduce lawlessness and rebellion? A field experiment with high-risk men in a fragile state. American Political Science Review 110(1): 1-17.
Blattman, Christopher \& Laura Ralston (2015) Generating employment in poor and fragile states: Evidence from labor market and entrepreneurship programs. Working paper (https://papers.ssrn.com/sol3/papers.cfm?abstract_ id=2622220).

Blei, David; Andrew Ng \& Michael Jordan (2003) Latent Dirichlet allocation. Journal of Machine Learning Research 3(January): 993-1022.

Böhnke, Jan Rasmus \& Christoph Zürcher (2013) Aid, minds, and hearts: The impact of aid in conflict zones. Conflict Management and Peace Science 30(5): 411-432.

Braithwaite, Alex \& Shane Johnson (2012) Space-time modeling of insurgency and counterinsurgency in Iraq. Journal of Quantitative Criminology 28(1): 31-48.

Brük, Tilman; Neil Ferguson, Wolfgang Stojetz \& Valeria Izzi (2016) Do jobs aid peace? The impact of employment interventions on peace, security and stability. Report for ILO, PBSO, UNDP, and WBG, Berlin (http://isd-center. org/wp-content/uploads/2016/09/Employment-Interven tions-and-Peace-Final-Report-Final-Version-2016-09-16. pdf).

Buhaug, Halvard; Lars-Erik Cederman \& Jan Ketil Rød (2008) Disaggregating ethno-nationalist civil wars: A dyadic test of exclusion theory. International Organization 62(3): 531-551.

Buhaug, Halvard; Scott Gates \& Päivi Lujala (2009) Geography, rebel capacity, and the duration of civil conflict. Journal of Conflict Resolution 53(4): 544-569.

CALL (2009) Commander's guide to money as weapons system. Center for Army Lessons Learned (http://www. acq.osd.mil/log/PS/ocs/cdg/MAAWSCdrHandbook. pdf).

Camerer, Colin \& Richard Thaler (1995) Anomalies: Ultimatums, dictators and manners. Journal of Economic Perspectives 9(2): 209-2019.

Cederman, Lars-Erik \& Manuel Vogt (2017) Dynamics and logics of civil war. Journal of Conflict Resolution 61(9): 1992-2016.

Cederman, Lars-Erik; Kristian Skrede Gleditsch \& Halvard Buhaug (2013) Inequality, Grievances, and Civil War. New York: Cambridge University Press.

Chandrasekaran, Rajiv (2012) Little America: The War Within the War for Afghanistan. New York: Knopf Doubleday.

Child, Travers (2014) Hearts and minds cannot be bought: Ineffective reconstruction in Afghanistan. Economics of Peace and Security 9(2): 43-49.

Collier, Paul \& Anke Hoeffler (2004) Greed and grievance in civil war. Oxford Economic Papers 56(4): 563-595.

Condra, Luke \& Jacob Shapiro (2012) Who takes the blame? The strategic effects of collateral damage. American Journal of Political Science 56(1): 167-187.

Crost, Benjamin; Joseph Felter \& Patrick Johnston (2014) Aid under fire: Development projects and civil conflict. American Economic Review 104(6): 1833-1856. 
Dollard, John Miller; Neal Doob, Leonard Mowrer \& Robert Sears (1939) Frustration and Aggression. New Haven, CT: Yale University Press.

Dube, Oeindrila \& Juan Vargas (2013) Commodity price shocks and civil conflict: Evidence from Colombia. Review of Economic Studies 80(4): 1384-1421.

Fearon, James \& David Laitin (2003) Ethnicity, insurgency, and civil war. American Political Science Review 97(1): $1-16$.

Fishstein, Paul (2012) Winning hearts and winds in Uruzgan province. Feinstein International Center (http://fic.tufts. edu/assets/Uruzgan-Report.pdf).

Fishstein, Paul \& Andrew Wilder (2012) Winning hearts and minds? Examining the relationship between aid and security in Afghanistan. Feinstein International Center (http:// fic.tufts.edu/assets/WinningHearts-Final.pdf).

Gerring, John (2007) Case Study Research: Principles and Practices. New York: Cambridge University Press.

Gesch, Dean; Kristine Verdin \& Susan K Greenlee (1999) New land surface digital elevation model covers the earth. Eos, Transaction, American Geophysical Union 80(6): 69-70.

GIROA (2008) Afghanistan National Development Strategy. Government of the Islamic Republic of Afghanistan (http://mcn.gov.af/Content/files/ANDSEn.pdf).

Gopal, Anand (2014) No Good Men Among the Living. New York: Metropolitan.

Gordan, Stuart (2011) Winning hearts and minds? Examining the relationship between aid and security in Afghanistan's Helmand province. Feinstein International Center (http:// www.operationspaix.net/DATA/DOCUMENT/ $4206 \sim \mathrm{v} \sim$ Winning_Hearts_and_Minds_Examining_ the_Relationship_between_Aid_and_Security_in_ Afghanistans_Helmand_Province.pdf).

Grossman, Herschell (1991) A general equilibrium model of insurrections. American Economic Review 61(4): 912-921.

Gurr, Ted ([1970] 2011) Why Men Rebel, 2nd edition. Boulder, CO: Paradigm.

Güth, Werner; Rolf Schmittberger \& Bernd Schwarze (1982) An experimental analysis of ultimatum bargaining. Journal of Economic Behavior and Organization 3(4): 367-388.

Gutting, Raynee \& Martin Steinwand (2017) Donor fragmentation, aid shocks, and violent political conflict. Journal of Conflict Resolution 61(3): 643-670.

Haushofer, Johannes; James Reisinger \& Jeremy Shapiro (2015) Your gain is my pain: Negative psychological externalities of cash transfers. Working paper (https:// www.princeton.edu/haushofer/publications/Haushofer_ Reisinger_Shapiro_Inequality_2015.pdf).

Hechter, Michael; Steven Pfaff \& Patrick Underwood (2016) Grievances and the genesis of rebellion: Mutiny in the Royal Navy, 1740 to 1820 . American Sociological Review 81(1): 165-189.

Hedgpeth, Dana \& Sarah Cohen (2008) Money as a weapon. Washington Post 11 August.
Henrich, Joseph (2000) Does culture matter in economic behavior? Ultimatum game bargaining among the Machiguenga of the Peruvian Amazon. American Economic Review 90(4): 973-978.

Horne, Nick (2012) Throwing money at the problem: US PRTs in Afghanistan. Snapshots of an Intervention: The Unlearned Lessons of Afghanistan's Decade of Assistance (2001-11) (http://aan-afghanistan.com/uploads/16Horne ThrowingMoneyattheProblem.pdf).

Iacus, Stefano; Gary King \& Giuseppe Porro (2012) Causal inference without balance checking: Coarsened exact matching. Political Analysis 20(1): 1-24.

Kalyvas, Stathis (2006) The Logic of Violence in Civil War. New York: Cambridge University Press.

Karell, Daniel (2015) Aid, power, and grievances: Lessons for war and peace from rural Afghanistan. Economics of Peace and Security 10(2): 43-52.

Karell, Daniel (2017) Local peace and contemporary conflict: Constructing commonality and exclusion during war in Afghanistan. Social Science Research 61(1): 75-97.

Kocher, Matthew; Thomas Pepinsky \& Stathis Kalyvas (2011) Aerial bombing and counterinsurgency in the Vietnam War. American Journal of Political Science 55(2): 201-218.

Lake, David (2010) The practice and theory of US statebuilding. Journal of Intervention \& Statebuilding 4(3): 257-284.

Lebovic, James (2010) The Limits of US Military Capability: Lessons from Vietnam and Iraq. Baltimore, MD: Johns Hopkins University Press.

Lichbach, Mark (1995) The Rebel's Dilemma. Ann Arbor, MI: University of Michigan Press.

Lyall, Jason (2009) Does indiscriminate violence incite insurgent attacks? Evidence from Chechnya. Journal of Conflict Resolution 53(3): 331-362.

Malkasian, Carter (2013) War Comes to Garmser. New York: Oxford University Press.

Martin, Mike (2014) An Intimate War: An Oral History of the Helmand Conflict. New York: Oxford University Press.

McColl, Robert (1969) The insurgent state: Territorial bases of revolution. Annals of the Association of American Geographers 59(4): 613-631.

Metternich, Nils; Cassy Dorff, Max Gallop, Simon Weschle \& Michael Ward (2013) Antigovernment networks in civil conflicts: How network structures affect conflictual behavior. American Journal of Political Science 57(4): 892-911.

Mohr, John \& Petko Bogdanov (2013) Topic models: What they are and why they matter. Poetics 41(6): 545-569.

Nepal, Mani; Alok Bohara \& Kishore Gawande (2011) More inequality, more killings: The Maoist insurgency in Nepal. American Journal of Political Science 55(4): 885-905.

Nielsen, Richard; Michael Findley, Zachary Davis, Tara Candland \& Daniel Nielson (2011) Foreign aid shocks as a cause of violent armed conflict. American Journal of Political Science 55(2): 219-232.

Nunn, Nathan \& Nancy Qian (2014) US food aid and conflict. American Economic Review 104(6): 1630-1666. 
Olson, Mancur (1965) The Logic of Collective Action. Cambridge, MA: Harvard University Press.

Raleigh, Clionadh \& Håvard Hegre (2009) Population size, concentration, and civil war: A geographically disaggregated analysis. Political Geography 28(4): 224-238.

Savun, Burcu \& Daniel Tirone (2011) Foreign aid, democratization, and civil conflict: How does democracy aid affect civil conflict? American Journal of Political Science 55(2): 233-246.

Schutte, Sebastian (2017) Violence and civilian loyalties. Journal of Conflict Resolution 61(8): 1595-1625.

Schutte, Sebastian \& Karsten Donnay (2014) Matched wake analysis: Finding causal relationships in spatiotemporal event data. Political Geography 41(July): 1-10.

Sexton, Renard (2016) Aid as a tool against insurgency: Evidence from contested and controlled territory in Afghanistan. American Political Science Review 110(4): 731-749.

SIGAR (2015) Quarterly report. Washington, DC: Special Inspector General for Afghanistan Reconstruction (https:// www.sigar.mil/pdf/quarterlyreports/2015-07-30qr.pdf).

Tokdemir, Efe (2017) Winning hearts \& minds (!): The dilemma of foreign aid in anti-Americanism. Journal of Peace Research 54(6): 819-832.

Warren, Zach (2014) Afghanistan in 2014: A Survey of the Afghan People. Kabul: Asia Foundation.

Weidmann, Nils (2015) On the accuracy of media-based conflict event data. Journal of Conflict Resolution 59(6): 1129-1149.
Weidmann, Nils (2016) A closer look at reporting bias in conflict event data. American Journal of Political Science 60(1): 206-218.

Weintraub, Michael (2016) Do all good things go together? Development assistance and insurgent violence in civil war. Journal of Politics 78(4): 989-1002.

Wimmer, Andreas (2013) Waves of War. New York: Cambridge University Press.

Wimmer, Andreas; Lars-Erik Cederman \& Brian Min (2009) Ethnic politics and armed conflict: A configurational analysis of a new global dataset. American Sociological Review 74(2): 316-337.

Wucherpfennig, Julian; Nils Weidmann, Luc Girardin, Lars-Erik Cederman \& Andreas Wimmer (2011) Politically relevant ethnic groups across space and time: Introducing the GeoEPR dataset. Conflict Management and Peace Science 28(5): 423-437.

DANIEL KARELL, PhD in Sociology (University of Washington, 2014); Assistant Professor, Division of Social Science, New York University Abu Dhabi (2016- ); significant work on this article was completed while Dr Karell was a Fung Global Fellow at Princeton University.

SEBASTIAN SCHUTTE, PhD in Political Science (ETH Zürich, 2014); Marie Curie Fellow at the University of Konstanz, Zukunftskolleg and Department of Politics and Public Administration (2016- ); current main interest: micro-dynamics of civil conflicts. 